\title{
Hepatitis $C$ virus infection among patients with diabetes mellitus in Dammam, Saudi Arabia
}

\author{
Ebtesam M. Ba-Essa', Eman I. Mobarak ${ }^{2}$ and Nasser M. Al-Daghri, $3,4^{*}$
}

\begin{abstract}
Background: Data regarding comorbidities of hepatitis $\mathrm{C}$ virus infection (HCV) in the kingdom of Saudi Arabia (KSA) are lacking. The present study aimed to determine the prevalence and risk factors of HCV among Saudi patients with diabetes mellitus (DM) in Dammam, KSA.

Methods: In this cross-sectional study done in 2011, a total of 1054 Saudi DM patients were randomly selected from the Diabetes Center in Dammam Medical Complex, KSA, for interview and HCV screening using the HCV Rapid Test. Positive cases were later confirmed via INNO-LIA HCV score line immune assay.

Results: Seropositivity of HCV was $1.9 \%$. DM duration of $>5$ years increased the probability of HCV risk to 3.7 fold while insulin users were 3.2 times more likely to have HCV infection. Increased hospital admission (3-4 times) also increased HCV risk by 11.5 times and 13.6 times among patients with $\geq 5$ admissions. Similarly, having 3-4 surgical procedures increased HCV risk by 8.6 times and 39.3 times with $\geq 5$ procedures. HCV transmission is 4 times more likely by blood transfusion. Those who shared personal items were 8.5 times more likely to have HCV. Tattooing increased HCV risk by 6.7 times. The likelihood of HCV infection was also higher among DM patients with liver diseases and elevated liver enzymes.

Conclusion: The study confirmed a significant association between HCV risk and DM. Frequency of HCV among DM Saudis was $1.9 \%$. Predictors of HCV among DM patients were sharing personal items, occupational exposure to blood or its products, elevated transaminases, tattooing, disease duration $>5$ years, increased hospital admission and blood transfusion.
\end{abstract}

Keywords: Hepatitis C, Risk factors, Insulin resistance, Diabetes, Dammam

\section{Background}

Diabetes mellitus (DM) is a global public health threat. In 2014, more than 387 million cases reported worldwide and is expected to rise by as much as 592 million by 2035 [1].

Hepatitis $\mathrm{C}$ virus (HCV) infection is another worldwide major health problem affecting more than 170 million, with $80 \%$ harboring chronic infection. It is a major cause of morbidity, mortality and is a main risk factor

\footnotetext{
* Correspondence: aldaghri2011@gmail.com

${ }^{3}$ Prince Mutaib Chair for Biomarkers of Osteoporosis, Biochemistry

Department, College of Science, King Saud University, Riyadh 11451, Saudi

Arabia

${ }^{4}$ Biomarkers Research Program, Biochemistry Department, College of Science,

King Saud University, Riyadh 11451, Saudi Arabia

Full list of author information is available at the end of the article
}

for acute hepatitis and chronic liver diseases including cirrhosis, liver cancer, and chronic kidney disease [2].

There are increasing reports indicating an association between $\mathrm{HCV}$ and type $2 \mathrm{DM}$ (T2DM). In controlled studies, individuals with $\mathrm{HCV}$ were observed to have increased T2DM risk [3, 4] and T2DM patients have at least a 2-fold greater risk of HCV infection [3, 5]. HCV induces impaired insulin signaling, insulin resistance (IR), disturbed glucose, protein and lipid metabolism as well as hepatic steatosis $[6,7]$. It has been suggested that the associations between DM, HCV, IR and steatosis cumulatively increases risk of progression to hepatic fibrosis and hepatocellular carcinoma as well as reduce virological response to interferon- $\alpha$-based therapy [7]. 
In the Kingdom of Saudi Arabia (KSA), DM is as a major public health problem with alarming rates [8]. Data regarding co-morbidity with $\mathrm{HCV}$ are lacking. The study therefore aims to determine the frequency and risk factors of HCV among Saudi patients with DM.

\section{Methods}

The present cross-sectional study was undertaken last 2011. Target population was all known DM patients attending the Diabetes Center in the Dammam Medical Complex, Dammam, KSA. A random sample of consenting Saudi patients were selected every other day to be included in the study. Response rate was $100 \%$. Enrolled patients were interviewed in privacy by the investigators using a generalized questionnaire that includes sociodemographic characteristics, intravenous drug use, family history for DM and other medical histories. History of previous exposure to possible risk factors for HCV infection (at least 6 months prior to interview) were also collected. Weight and height were measured and noted.

A drop of whole blood per patient was collected by the investigators from the blood samples drawn for routine lab investigations. Following the manufacturer's instructions, blood was tested for HCV antibodies (qualitative detection) using "The Hepatitis C Virus Rapid Test Device" (whole blood/serum/plasma) [ACON Laboratories, Inc. San Diego, CL, USA]. This test has an accuracy of $99.3 \%$, sensitivity of $99 \%$ and specificity of $98.6 \%$. Patients with positive results were referred to the hospital central lab for confirmation via INNO-LIA HCV score line immune assay [Innogenetics, Belgium]. Confirmed $\mathrm{HCV}$ patients were referred to Hepatology department for management.

Patient records were obtained after the laboratory results of the routine lab investigations performed at the date of the interview [serum levels of liver enzymes; alanine aminotransferase (ALT) and aspartate aminotransferase (AST) and creatinine] were released. Levels of these markers were judged based on the upper limit of the reference normal range according to the used kits. High lipid profile was defined as $>200 \mathrm{mg} / \mathrm{dl}$ for cholesterol, >150 mg/dl for triglycerides, $>130 \mathrm{mg} / \mathrm{dl}$ for lowdensity lipoprotein cholesterol (LDL-C) [9]. Cut off for low level high density lipoprotein cholesterol (HDL-C) was $<50 \mathrm{mg} / \mathrm{dl}$ for females and $40 \mathrm{mg} / \mathrm{dl}$ for males [9]. Glycemic control was classified into uncontrolled if $\mathrm{HbAc}_{1} \geq 7 \%$ and controlled if $\mathrm{HbAc}_{1}<7 \%$ [10]. The available findings of abdominal ultrasonic examination were also recorded.

Body mass index (BMI) was calculated as the ratio of the weight $(\mathrm{kg})$ to the height $(\mathrm{m})^{2}$ then classified as underweight $\left(<18.5 \mathrm{~kg} / \mathrm{m}^{2}\right)$, normal $\left(18.5-<25 \mathrm{~kg} / \mathrm{m}^{2}\right)$, overweight $\left(25-<30 \mathrm{~kg} / \mathrm{m}^{2}\right)$, grade I obese $\left(30-<35 \mathrm{~kg} / \mathrm{m}^{2}\right)$, grade II obese $\left(35-<40 \mathrm{~kg} / \mathrm{m}^{2}\right)$ and grade III obese $\left(\geq 40 \mathrm{~kg} / \mathrm{m}^{2}\right)[11]$.

\section{Statistical analysis}

Data were analyzed using SPSS version 16.0 (SPSS Inc. Chicago, IL, USA) and the Epi-info (CDC, Atlanta, GA) [Open Source Epidemiologic Statistics for Public Health, Version 2.3.1. www.OpenEpi.com, updated 2011/23/06, accessed 2012/06/14]. The mean, standard deviation, median, odds ratio corresponding $95 \%$ confidence interval (95\% CI) were computed. Chi-square and Student's $t$-test were the used tests of significance. Logistic regression analysis was carried out using all measured variables to identify the relationship with other variables. The regression analysis was performed using the Enter method. A $P$ value of $<0.05$ was considered statistically significant. Only significant predictors were presented with odd ratios and $95 \%$ confidence intervals. Non-significant predictors with $p$-values $>0.05$ were not presented.

\section{Results}

\section{General characteristics}

The present study included 1057 Saudi DM patients (32.2\% males and $67.8 \%$ females). The mean age of enrolled patients was $48.42 \pm 13.70$ year $(\min =12$, $\max =$ 87 years). At least $4.1 \%$ of the subjects were minors (10-19 years) and 5.0\% were 20-29 years old. Adults between 30 and 39 years were $11.8 \%$. The largest proportion (79.1\%) of patients were 40 years old and above. Majority of the patients were married (91.8\%). More than $40 \%$ were illiterate and $47.2 \%$ attended schools. Only $5.0 \%$ were university graduates or higher. Majority $(74.9 \%)$ were unemployed and were non-smokers (81.93\%). Overall, $89 \%$ of DM patients were either overweight or obese (BMI $\geq 25 \mathrm{~kg} / \mathrm{m}^{2}$; $n=1028)$.

\section{Disease profile}

DM duration ranged from 1 month to 45 years $(9.88 \pm$ 7.84 years). T2DM was the most common (92.2\%). Patients were treated with insulin (27.3\%), oral hypoglycemic drugs (56.8\%), combination drugs (9.8\%), or just with diet control (6.1\%). Glycemic control was achieved by $64.3 \%$ of patients whereas $35.7 \%$ were uncontrolled. Most patients $(76.1 \%)$ had a positive family history of DM.

\section{History of exposure to risk factors for HC}

Of the 969 married patients, $3.2 \%$ had a partner with known HCV. Exposure to dental procedure was given by $57.7 \%$ of the patients. Sharing personal items such as shaving devices/tooth brushes were reported by $2.3 \%$ of patients. A small proportion received a type of injection. The majority of patients (81.9\%) were previously hospitalized at least once in their lifetime with a mean of $1.7 \pm 1.4$ 
$(\min =1, \max =9)$ admissions. Two thirds of patients $(66.2 \%)$ reported 1 to 8 surgical procedures $(1.4 \pm 0.8)$. Half $(50.0 \% ; n=646)$ of married women had a history of abortion. Recipients of blood transfusion were $17.5 \%$. A minority $(0.8 \%)$ were on dialysis and $0.3 \%(n=3)$ had a previous diagnosis of hepatitis $B$ infection. Liver diseases (other than $\mathrm{HCV}$ ) were reported by $3.3 \%$. Only $1.3 \%$ of patients were exposed to blood or its products in occupational settings. Tattooing was reported by $1.8 \%$.

Women were more likely to be exposed to HCV risk factors than men. Women were 4.5 times (Confidence Interval $(\mathrm{CI})=1.3-15.1)$ more likely to have a husband with $\mathrm{HCV}$. They were also more exposed to dental procedures [Odds Ratio (OR) 10.9 (CI = 8.1-14.9)], hospitalization [OR 1.7 $(\mathrm{CI}=1.3-2.4)$ and surgical procedures [OR $2.0(\mathrm{CI}=1.5-$ 2.6)]. The probability was also higher among women with history of blood transfusion [OR $3.4(\mathrm{CI}=2.2-5.3)$ ], injections [OR $18.0(\mathrm{CI}=4.4-73.9)]$ and intravenous drug use [OR $32.1(\mathrm{CI}=4.4-232.4)]$. On the other hand, men were 4.4 times $(\mathrm{CI}=1.9-10.3)$ more likely to share personal items. No differences were observed regarding glycemic control, occupational exposure to blood or its products, tattooing, dialysis, history of hepatitis B or other liver diseases.

\section{Clinical laboratory and imaging findings}

Laboratory results revealed both increased serum transaminases among $5.8 \%$ and creatinine among $8.2 \%$ of patients. Abnormal lipid profile was observed in $40.6 \%$ patients with high serum cholesterol, $35.8 \%$ with high triglycerides, $39.7 \%$ with high LDL-cholesterol and 47.9 \% with low HDL-cholesterol. Abnormal abdominal ultrasound was reported by 105 out of 210 participants that suggested fatty liver $(49.5 \%)$ and liver cirrhosis (0.5\%).

\section{Prevalence of HCV}

Using the Rapid screening test, 22 (2.1\%) of the patients were found to be seropositive for $\mathrm{HCV}$. On applying confirmatory test, only 20 cases were true positive resulting in a frequency of $1.9 \%$ without significant difference between type 1 and type 2 DM.

\section{Risk factors for HCV}

Patients who tested positive for $\operatorname{HCV}(51.6 \pm 11.7$ years $)$ were older than those who tested negative (48.36 \pm 13.73 years). Table 1 shows that DM duration $>5$ years increased the risk of' HCV 3.7 folds $(\mathrm{CI}=1.1-12.7)$. Insulin users were 3.2 times $(\mathrm{CI}=1.3-8.1)$ more likely to have $\mathrm{HCV}$ than non-users. The frequency of hospitalization and surgical procedures were significantly associated with $\mathrm{HCV}$ risk. Those who were admitted to hospital 3-4 times were 11.5 times ( $\mathrm{CI}=1.4-94.4)$ more likely to have $\mathrm{HCV}$ and the risk increases to 13.6 ( $\mathrm{CI}=1.5-$ 123.9) if admitted $>5$ times. Similarly, surgical procedures increased the risk for $\mathrm{HCV}$ by 8.6 folds $(\mathrm{CI}=1.7-44.2)$ with $3-4$ procedures and 39.3 folds $(\mathrm{CI}=3.1-495.0)$ with $\geq 5$ procedures than those who never had surgery. Blood transfusion quadruples $(\mathrm{OR}=$ 4.0, $\mathrm{CI}=1.6-9.8)$ the probability of HCV infection. Those who shared personal items with others were 8.5 times $(\mathrm{CI}=2.3-31.4)$ more likely to have $\mathrm{HCV}$ than those who didn't. Tattooing also increased the risk of $\mathrm{HCV}$ to 6.7 folds $(\mathrm{CI}=1.4-31.0)$. The likelihood of $\mathrm{HCV}$ is also higher among DM patients with other liver diseases $(\mathrm{OR}=19.4 ; 95 \% \mathrm{CI}=7.2-52.4)$ and elevated liver enzymes $(\mathrm{OR}=12.3 ; 95 \% \mathrm{CI}=4.8-31.5)$.

Significant independent predictors of HCV among patients are shown in Table 2 (non-significant predictors were not presented). These include sharing articles $(\mathrm{OR}=27.5$, $\mathrm{CI}=5.4-140.0$ ), exposure to blood or its products in occupational setting $(\mathrm{OR}=23.8, \mathrm{CI}=2.2-257.7)$, elevated liver enzymes $(\mathrm{OR}=19.1, \mathrm{CI}=6.0-61.1)$, tattooing $(\mathrm{OR}=$, $\mathrm{CI}=7.7$ (1.4-44.0), diseases duration $>5$ years $(\mathrm{OR}=$ 6.8, $\mathrm{CI}=1.5-31.5)$, hospitalization $>2$ times $(\mathrm{OR}=4.7$, $\mathrm{CI}=1.6-13.6)$, and blood transfusion ( $\mathrm{OR}=3.67, \mathrm{CI}=$ $1.2-11.0$ ) This model classifies correctly $98.5 \%$ of cases.

\section{Discussion}

There is evidence that DM patients are at higher risk of acquiring $\mathrm{HCV}$ infection and may be related to either the disease itself or frequent parenteral exposure [12]. However, some controlled studies failed to support this hypothesis [13]. The prevalence rate of $\mathrm{HCV}(1.9 \%)$ in the present study is much lower than the $36 \%$ reported from Pakistan [12] and $11 \%$ reported from Nigeria [14]. It is also lower than the rates reported in France, UK and USA, which ranged from $3 \%$ to $8 \%[3,15,16]$. However the rate revealed by the present study is comparable to the $1.3 \%$ reported from Tunisia [14] and the $1.65 \%$ reported in Greece [17].

The rate of $\mathrm{HCV}$ among blood donors in the central blood bank of Dammam was taken as control. The screening of 10,853 apparently healthy blood donors during the year of study identified only 8 confirmed cases of HCV $(0.074 \%)$ [Obtained from blood bank records through personal communication]. As for the whole Eastern province, the catchment area of Dammam Diabetes Center, the recorded rate of HCV among blood donors was $0.59 \%$ (79 out of 13,443 during 2001) [18]. According to the Ministry of Health, 299 (0.011 \%) cases of $\mathrm{HCV}$ have been reported in the same region $(2,776,046$ inhabitants) in 2011 [19]. Hence, the present study provides evidence of the higher likelihood of $\mathrm{HCV}$ infection among DM patients.

The reported HCV cases in KSA are low (0.0-0.02 \%, in 2011) [19] and declining [18-20], probably due to routine screening of blood donors, low prevalence of intravenous addiction and wide practice of infection control procedures 
Table 1 Distribution of Patients and HCV risk

\begin{tabular}{|c|c|c|c|c|c|c|}
\hline \multirow[t]{2}{*}{ Factor } & \multicolumn{2}{|c|}{ Positive to HCV } & \multicolumn{2}{|c|}{ Negative to HCV } & \multirow[t]{2}{*}{ OR $(95 \% \mathrm{Cl})$} & \multirow[t]{2}{*}{$X^{2}$ ( $P$ value $)$} \\
\hline & No & $\%$ & No & $\%$ & & \\
\hline \multicolumn{7}{|l|}{ Sex: } \\
\hline Male $^{a}$ & 5 & 25.0 & 335 & 32.3 & $1.4(0.5-4.0)$ & $0.48(0.49)$ \\
\hline Female & 15 & 75.0 & 702 & 67.7 & & \\
\hline \multicolumn{7}{|l|}{ Marital status: } \\
\hline Married & 20 & 100.0 & 949 & 91.5 & $0.98(0.97-0.99)$ & $1.85(0.25)^{\mathrm{b}}$ \\
\hline Non married ${ }^{a}$ & 0 & 0.0 & 88 & 8.5 & & \\
\hline \multicolumn{7}{|l|}{ Employment: } \\
\hline$Y_{e s}^{a}$ & 2 & 10.0 & 263 & 25.4 & $3.1(0.7-13.3)$ & $2.47(0.088)^{b}$ \\
\hline No & 18 & 90.0 & 774 & 74.6 & & \\
\hline \multicolumn{7}{|l|}{ Type: } \\
\hline Type I & 3 & 15. 0 & 79 & 7.6 & $2.1(0.6-7.5)$ & $1.49(0.20)^{b}$ \\
\hline Type $\|^{a}$ & 17 & 85.0 & 958 & 92.4 & & \\
\hline \multicolumn{7}{|l|}{ Insulin Treatment: } \\
\hline Yes & 13 & 65.0 & 380 & 36.6 & $3.2(1.3-8.1)$ & $6.76(0.009)^{*}$ \\
\hline $\mathrm{No}^{\mathrm{a}}$ & 7 & 35.0 & 657 & 63.4 & & \\
\hline Glycemic control status: & & & & & $0.97(0.4-2.5)$ & $0.004(0.950)$ \\
\hline Controlled $^{\mathrm{a}}$ & 13 & 65.0 & 667 & 64.3 & & \\
\hline Uncontrolled & 7 & 35.0 & 370 & 35.7 & & \\
\hline \multicolumn{7}{|l|}{ Duration of disease: } \\
\hline$>5$ years & 17 & 85.0 & 826 & 60.6 & $3.7(1.1-12.7)$ & $4.93(0.019)^{b^{*}}$ \\
\hline$\leq_{5}$ years $^{\mathrm{a}}$ & 3 & 15.0 & 409 & 39.4 & & \\
\hline \multicolumn{7}{|c|}{ Hepatitis C partner: $^{\complement}((n=969)$} \\
\hline Yes & 1 & 5.0 & 30 & 3.2 & $1.6(0.2-12.4)$ & $0.214(0.482)^{b}$ \\
\hline $\mathrm{No}^{\mathrm{a}}$ & 19 & 95.0 & 919 & 96.8 & & \\
\hline \multicolumn{7}{|l|}{ Occupational exposure: } \\
\hline Yes & 1 & 5.0 & 13 & 1.3 & $4.2(0.5-33.3)$ & $2.11(0.236)^{b}$ \\
\hline $\mathrm{No}^{\mathrm{a}}$ & 19 & 95.0 & 1024 & 98.7 & & \\
\hline Dental procedure: & & & & & $0.9(0.4-2.2)$ & $0.061(0.804)$ \\
\hline Yes & 11 & 55.0 & 599 & 57.76 & & \\
\hline $\mathrm{No}^{\mathrm{a}}$ & 9 & 45.0 & 438 & 42.24 & & \\
\hline Injection: & & & & & $0.7(0.1-5.5)$ & $0.096(1.000)^{b}$ \\
\hline Yes & 1 & 5.0 & 70 & 6.8 & & \\
\hline $\mathrm{No}^{\mathrm{a}}$ & 19 & 95.0 & 967 & 93.2 & & \\
\hline IV Drug Use: & & & & & $0.8(0.1-6.3)$ & $0.034(1.000)^{b}$ \\
\hline Yes & 1 & 5.0 & 62 & 6.0 & & \\
\hline $\mathrm{No}^{\mathrm{a}}$ & 19 & 95.0 & 975 & 94.0 & & \\
\hline \multicolumn{7}{|l|}{ Hospitalization: } \\
\hline Yes & 19 & 95.0 & 847 & 81.7 & $4.3(0.6-32.0)$ & $2.352(0.151)^{b}$ \\
\hline $\mathrm{No}^{\mathrm{a}}$ & 1 & 5.00 & 190 & 18.3 & & \\
\hline \multicolumn{7}{|l|}{ Number of admissions: } \\
\hline $0^{a}$ & 1 & 5.0 & 190 & 18.3 & & \\
\hline $1-2$ times & 8 & 40.0 & 675 & 65.1 & $2.3(0.3-18.1)$ & $0.614(0.692)$ \\
\hline
\end{tabular}


Table 1 Distribution of Patients and HCV risk (Continued)

\begin{tabular}{|c|c|c|c|c|c|c|}
\hline $3-4$ times & 7 & 35.0 & 116 & 11.2 & $11.5(1.4-94.4)$ & $8.047(0.007)^{*}$ \\
\hline $5+$ times & 4 & 20.0 & 56 & 5.4 & $13.6(1.5-123.9)$ & $8.825(0.012)^{*}$ \\
\hline \multicolumn{7}{|l|}{ Surgery: } \\
\hline Yes & 17 & 85.0 & 683 & 65.9 & $2.9(0.9-10.1)$ & $3.21(0.094)^{b}$ \\
\hline $\mathrm{No}^{\mathrm{a}}$ & 3 & 15.0 & 354 & 34.1 & & \\
\hline \multicolumn{7}{|c|}{ Number of operations: } \\
\hline $0^{\mathrm{a}}$ & 3 & 15.0 & 354 & 34.1 & $2.40(0.7-8.5)$ & $1.97(0.195)$ \\
\hline $1-2$ times & 13 & 65.0 & 639 & 61.6 & $8.6(1.7-44.2)$ & $9.50(0.020)^{*}$ \\
\hline $3-4$ times & 3 & 15.0 & 41 & 4.0 & $39.3(3.1-495.0)$ & $21.07(0.044)^{*}$ \\
\hline $5+$ times & 1 & 5.0 & 3 & 0.3 & & \\
\hline \multicolumn{7}{|c|}{ Abortion: ${ }^{d}(n-646)$} \\
\hline Yes & 9 & 69.2 & 314 & 49.6 & $2.3(0.7-7.5)$ & $1.96(0.262)$ \\
\hline $\mathrm{No}^{\mathrm{a}}$ & 5 & 30.8 & 319 & 50.4 & & \\
\hline \multicolumn{7}{|c|}{ Blood Transfusion: } \\
\hline Yes & 9 & 45.0 & 176 & 17.0 & $4.0(1.6-9.8)$ & $10.68(0.001)^{*}$ \\
\hline $\mathrm{No}^{\mathrm{a}}$ & 11 & 55.0 & 861 & 83.0 & & \\
\hline \multicolumn{7}{|c|}{ Sharing personal items: } \\
\hline Yes & 3 & 15.0 & 21 & 2.0 & $8.5(2.3-31.4)$ & $14.89(0.009)^{b^{*}}$ \\
\hline $\mathrm{No}^{\mathrm{a}}$ & 17 & 85.0 & 1016 & 98.0 & & \\
\hline \multicolumn{7}{|l|}{ Tattoo: } \\
\hline Yes & 2 & 10.0 & 17 & 1.6 & & \\
\hline $\mathrm{No}^{\mathrm{a}}$ & 18 & 90.0 & 1020 & 98.4 & $6.7(1.4-31.0)$ & $7.77(0.048)^{b^{*}}$ \\
\hline \multicolumn{7}{|l|}{ Liver disease: } \\
\hline Yes & 7 & 35.0 & 28 & 2.7 & $19.4(7.2-52.4)$ & $63.94(<0.001)^{*}$ \\
\hline $\mathrm{No}^{\mathrm{a}}$ & 13 & 65.0 & 1009 & 97.3 & & \\
\hline \multicolumn{7}{|c|}{ Elevated liver enzymes: $(n=1015)$} \\
\hline Yes & 8 & 40.0 & 51 & 5.1 & $12.3(4.8-31.5)$ & $43.55(<0.001)^{*}$ \\
\hline $\mathrm{No}^{\mathrm{a}}$ & 12 & 60.0 & 944 & 94.9 & & \\
\hline \multicolumn{7}{|c|}{ Positive US finding: $(n=210)$} \\
\hline Yes & 1 & 16.7 & 104 & 51.0 & $0.2(0.02-1.7)$ & $2.75(0.212)^{b}$ \\
\hline No ${ }^{a}$ & 5 & 83.3 & 100 & 49.0 & & \\
\hline \multicolumn{7}{|c|}{ Elevated creatinine: $(n=1024)$} \\
\hline Yes & 3 & 15.8 & 81 & 8.1 & $2.1(0.6-7.5)$ & $1.48(0.200)^{b}$ \\
\hline $\mathrm{No}^{\mathrm{a}}$ & 16 & 84.2 & 924 & 91.9 & & \\
\hline \multicolumn{7}{|l|}{ Dialysis: } \\
\hline Yes & 1 & 5.0 & 7 & 0.7 & $7.7(0.9-66.1)$ & $4.89(0.142)^{b}$ \\
\hline $\mathrm{No}^{\mathrm{a}}$ & 19 & 95.0 & 1030 & 99.3 & & \\
\hline Total & 20 & 100 & 1037 & 100 & & \\
\hline
\end{tabular}

${ }^{\text {a Reference category }}$

${ }^{b}$ Exact test

${ }^{c}$ Calculated for married $(n=969)$

dEach category was tested against reference category; Calculated for females $(n=646)$; *Statistically significant

among medical personnel. Nevertheless, it should be noted that intravenous addiction is still a major factor for $\mathrm{HCV}$ transmission and as such, patients who confide such information should be further investigated to track and identify other users who are potential carriers of HCV. Socioeconomic development, mass education and increased awareness of the disease also played a role $[20,21]$ in keeping the prevalence of $\mathrm{HCV}$ at bay. 
Table 2 Predictors of HCV

\begin{tabular}{lcll}
\hline Predictor & Odds ratio & $\begin{array}{l}\text { Adjusted odds ratio } \\
(95 \% \mathrm{Cl})\end{array}$ & $P$ value \\
\hline Sharing articles & 3.32 & $27.53(5.42-140.00)$ & $<0.001$ \\
$\begin{array}{l}\text { Occupational exposure } \\
\text { to blood }\end{array}$ & 3.17 & $23.80(2.20-257.72)$ & 0.009 \\
Elevated liver enzymes & 2.95 & $19.13(5.99-61.10)$ & $<0.001$ \\
Tattooing & 2.05 & $7.74(1.36-43.96)$ & 0.021 \\
Disease duration > 5 years & 1.92 & $6.82(1.48-31.47)$ & 0.014 \\
Hospitalization >2 times & 1.55 & $4.71(1.63-13.61)$ & 0.004 \\
Blood transfusion & 1.30 & $3.67(1.23-10.95)$ & 0.020
\end{tabular}

$\mathrm{R}^{2}=0.055$

Adjusted $\mathrm{R}^{2}=0.323$

$X^{2}(p$ value $)=57.133(<0.001)$

Model sensitivity $=98.5 \%$

In the present study, sharing personal items that may be contaminated with infected blood and tattooing were defined as HCV predictors. The risk of $\mathrm{HCV}$ continues to be a great occupational threat [22]. In agreement, exposure in occupational setting among the studied patients was a predictor for $\mathrm{HCV}$. Failure to adhere to universal precautions promote exposure to potentially infectious body fluids [22]. Consequently, blood transfusion was also identified as a predictor of $\mathrm{HC}[17,23]$ as well as increased hospital admission [24]. In the present work, HCV risk was significantly associated with both hospitalization and frequency of surgical operations. Parallel findings were previously observed [23]. These suggest a nosocomial source of HCV infection in chronically admitted DM patients.

In agreement with prior investigators $[4,13]$ who observed increased $\mathrm{HCV}$ positivity with increasing age, patients positive for $\mathrm{HCV}$ were older than those who tested negative. The higher frequency in older age may be explained by more exposure to risk factors [5]. The studied women had a higher rate of seropositivity compared to men. Ndako et al. [14] recorded the same finding, while others observed a significant association of HCV with male sex $[4,5]$. The present finding may be explained by the current significant female predominance regarding exposure to blood transfusion, hospitalization, surgical interference, parenteral injections and dental therapy which are known risk factors for HCV and may be related to their gynecological or obstetric history.

Consistent with Sotiropoulos et al. [17], the present study did not show an association between $\mathrm{HCV}$ and the type of DM, unlike the studies done by Jadoon et al. [5], Ndako et al. [8] and Ali et al. [12] who demonstrated a link between $\mathrm{HCV}$ and T2DM. Higher infection among insulin users may be linked to more frequent exposure to insulin injections and finger sticks for monitoring blood glucose [10] where unsafe injections or sharing contaminated equipment promote infection [2]. In contrast, Rudoni et al. [15] reported a negative association between $\mathrm{HC}$, mode of treatment and use of finger stick devices in hospitalized patients.

Association between chronicity of DM and HCV in the studied patients may reflect increased exposure for HCV infection $[8,20]$. Other studies didn't support this finding $[13,17]$. HCV had no association with glycemic control status in the present study whereas increased risk of $\mathrm{HCV}$ was associated with good control in some studies [5] and with poor control in others [13].

Chronic elevations of transaminases are common in both $\mathrm{DM}$ and $\mathrm{HCV}$ even without clinical manifestations in the liver $[16,25]$. In the present study, elevated transaminases were a predictor for HCV infection, reflecting that $\mathrm{HCV}$ infection maybe responsible for liver function abnormality. Consistent findings were observed in other studies [16, 17]. Hence, screening for HCV among DM patients can be conducted using liver function tests.

The authors acknowledge some limitations. The predictors of $\mathrm{HCV}$ in the present cohort, while identified based on statistical significance had wide confidence intervals and therefore should be interpreted with caution. Nevertheless, these risk factors are in agreement with several other epidemiologic data and therefore still has enough clinical precision to make decisions on how best to proceed if such $\mathrm{HCV}$ risk factors are present in every patient. Further information may still be needed.

\section{Conclusion}

The study confirmed a higher rate and a significant association between HCV and DM in Saudi patients in Dammam, KSA. The present study recommends screening for $\mathrm{HCV}$ among DM patients with elevated serum transaminases or those having DM for $>5$ years. $\mathrm{HCV}$ awareness and prevention campaign for all chronic DM patients are encouraged.

\section{Abbreviations}

ALT, alanine transferase; AST, aspartate aminotransferase; BMI, body mass index; $\mathrm{Cl}$, confidence interval; DM, diabetes mellitus; $\mathrm{HCV}$, hepatitis C virus; HDL, high density lipoprotein; KSA, Kingdom of Saudi Arabia; LDL, low density lipoprotein; OR, odds ratio; T2DM, type 2 diabetes mellitus

\section{Acknowledgements}

The authors acknowledge Dr. Sahar Abdulrahmam, Dammam Medical Complex, Dammam, KSA for helping in data collection. Sincere gratitude goes to Prof. Randa Youssef, Community medicine Department, Faculty of Medicine, Alexandria University, and Alexandria, Egypt for revising the manuscript and for her valuable notes. Gratitude also goes to Dr.

Mohammed Al-Harbi, Diabetes Centers and Units Administration, Ministry of Health, Riyadh, Saudi Arabia for his advises.

\section{Funding}

The project was supported by the Deanship of Scientific Research, Prolific Research Group Program (PRG-1436-15), Vice Rectorate for Graduate Studies and Scientific Research in King Saud University (KSU), Riyadh, Saudi Arabia. 


\section{Availability of data and materials}

All relevant and supporting data are contained within the manuscript.

\section{Authors' contributions}

EMB and EIM conceptualized the study, performed the experiments statistics and wrote the manuscript. NMA provided intellectual input and contributed to writing the final version of the manuscript. All authors read and approved the final manuscript.

\section{Competing interests}

The authors declare that they have no competing interests.

\section{Consent for publication}

Not applicable.

\section{Ethics approval and consent to participate}

The study was reviewed and approved by the Ethical Research Committees of Dammam Medical Complex in KSA and Alexandria Faculty of Medicine in Egypt. Confidentiality and anonymity was assured for each patient with respect to the information provided.

\section{Author details}

'Dammam Medical Complex, Dammam, Saudi Arabia. ${ }^{2}$ Community Medicine Department, Faculty of Medicine, Alexandria University, Alexandria, Egypt. ${ }^{3}$ Prince Mutaib Chair for Biomarkers of Osteoporosis, Biochemistry Department, College of Science, King Saud University, Riyadh 11451, Saudi Arabia. ${ }^{4}$ Biomarkers Research Program, Biochemistry Department, College of Science, King Saud University, Riyadh 11451, Saudi Arabia.

Received: 29 May 2015 Accepted: 21 July 2016

Published online: 27 July 2016

\section{References}

1. International Diabetes Federation. Diabetes Atlas, 2014 Update, (https://www. idf.org/sites/default/files/Atlas-poster-2014 EN.pd. Accessed 12 Oct 2015).

2. World Health Organization. Hepatitis C. Fact sheet number 164, 2011. (http:// www.who.int/mediacentre/factsheets/fs164/en/, Accessed 15 Mar 2015).

3. Mason AL, Lau JY, Hoang N, Qian K, Alexander GJ, Xu L, et al. Association of diabetes mellitus and chronic hepatitis $C$ virus infection. Hepatology. 1999;29:328-33.

4. Elhawary El, Mahmoud GF, El-Daly MA, Mekky FA, Esmat GG, Abdel-hamid M. Association of HCV with diabetes mellitus: an Egyptian case-control study. Virol J. 2011:8:367.

5. Jadoo NA, Shahzad MA, Yaqoob R, Hussain M, Ali N. Seroprevalence of hepatitis $C$ in type 2 diabetes: evidence for a positive association. Virol J. 2010;7:304.

6. Gutiérrez-Grobe Y, Ponciano-Rodríguez G, Méndez-Sánchez N. Viral hepatitis infection and insulin resistance: a review of the pathophysiological mechanisms. Salud Publica Mex. 2011;53 Suppl 1:\$46-51.

7. Francesco Negro F, Alaei M. Hepatitis C virus and type 2 diabetes. World J Gastroenterol. 2009;15(13):1537-47.

8. Al-Daghri NM, Al-Attas OS, Alokail MS, Alkharfy KM, Yousef M, Sabico SL, Chrousos GP. Diabetes mellitus type 2 and other chronic non-communicable diseases in the central region, Saudi Arabia (Riyadh cohort 2): a decade of an epidemic. BMC Med. 2011;9:76.

9. Khatib OMN (ed.) Guidelines for the prevention, management and care of diabetes mellitus. World Health Organization, Regional Office for the Eastern Mediterranean. Technical Publications Series 2006, No. 32. http://bibliotecadigital. puc-campinas.edu.br/services/e-books/9789290214045_eng.pdf.

10. American Diabetes Association. Standards of medical care in diabetes-2011. Diabetes Care. 2011;34 suppl 1:s11-61.

11. World Health Organization. Global data base on body mass index. BMI classification. Retrieved from http://apps.who.int/bmi/index.jsp?introPage=intro_3. html

12. Ali SS, Ali IS, Amir AH, Jadoon Z, Inayatullah S. Frequency of hepatitis C infection in diabetic patients. JAMC. 2007:19(1):46-9.

13. Kaabia N, Bin Jaziz E, Slim I, Fodha I, Hachfi W, Gaha R, et al. Association of hepatitis C virus infection and diabetes in central Tunisia. World J Gastroenterol. 2009;15(22):2778-81.
14. Ndako JA, Echeonwu GO, Shidali NN, Bichi IA, Paul GA, Ema OE, et al. Occurrence of Hepatitis C Virus infection in type 2 diabetic patients attending Plateau state specialist hospital Jos Nigeria. Virol J. 2009;6:98.

15. Rudoni S, Petit JM, Bour JB, Aho LS, Castaneda A, Vaillant G, et al. HCV infection and diabetes mellitus: influence of the use of finger stick devices on nosocomial transmission. Diabetes Metab. 1999;25(6):502-5.

16. Gray H, Wreghitt T, Stratton IM, Alexander GJ, Turner RC, O'Rahilly S. High prevalence of hepatitis c infection in Afro-Caribbean patients with type 2 diabetes and abnormal liver function tests. Diabet Med. 1995;12(3):244-9.

17. Sotiropoulos A, Peppas TA, Skliros E, Apostolou O, Kotsini V, Pappas SI. Low prevalence of hepatitis $C$ virus infection in Greek diabetic patients. Diabet Med. 1999;16:250-2.

18. Bashawri LA, Fawaz NA, Ahmad MS, Qadi AA, Almawi WY. Prevalence of seromarkers of HBV and HCV among blood donors in eastern Saudi Arabia, 1998-2001. Clin Lab Haematol. 2004;26(3):225-8.

19. General Department of Statistics and Information, Ministry of Health, Kingdom of Saudi Arabia, Ministry of Health, Health Statistical Year Book, 1432/2011. http://www.moh.gov.sa/Ministry/Statistics/book/flash/1432/ moh_Report_1432

20. Abdullah SM. Prevalence of hepatitis $B$ and $C$ in donated blood from Jazan region of Saudi Arabia. Malays J Med Sci. 2013;20(2):41-6.

21. Shobokshi OA, Serebour FE, Al-Drees AZ, Mitwalli AH, Qahtani A, Skakni LI. Hepatitis C virus seroprevalence rate among Saudis. Saudi Med J. 2003;24 Suppl 2:S81-6.

22. Cosens B, Kulkarni R. Needle-stick Guideline. Electronic version: http:// emedicine.medscape.com/article/784812 (last accessed 20/3/2015)

23. Cardinal GF, Di Martino V, Lambrey G, Nalet B, Anciaux ML. Prevalence of hepatitis $C$ infection and risk factors in hospitalized diabetic patients: results of a cross-sectional study. Eur J Gastroenterol Hepatol. 2008;20(9):829-36.

24. Martínez-Bauer E, Forns X, Armelles M, Planas R, Solà R, Vergara M, et al. Hospital admission is a relevant source of hepatitis $C$ virus acquisition in Spain. J Hepatol. 2008;48(1):20-7.

25. Harris EH. Elevated Liver Function Tests in Type 2 Diabetes. Clinical Diabetes. 2005;23(3):115-9.

\section{Submit your next manuscript to BioMed Central and we will help you at every step:}

- We accept pre-submission inquiries

- Our selector tool helps you to find the most relevant journal

- We provide round the clock customer support

- Convenient online submission

- Thorough peer review

- Inclusion in PubMed and all major indexing services

- Maximum visibility for your research

Submit your manuscript at www.biomedcentral.com/submit 